\title{
Voltammetric Determination of Nitrophenols at a Nickel Dimethylglyoxime Complex - Gold Nanoparticle Modified Glassy Carbon Electrode
}

\author{
F.O.G. Olorundare ${ }^{1}$, D. Nkosi ${ }^{1, *}$ and O.A Arotiba ${ }^{1,2, *}$ \\ ${ }^{1}$ Department of Applied Chemistry, University of Johannesburg, South Africa \\ ${ }^{2}$ Centre for Nanomaterials Science Research, University of Johannesburg, South Africa \\ *E-mail: oarotiba@uj.ac.za, dnkosi@uj.ac.za
}

doi: $10.20964 / 2016.09 .47$

Received: 17 May 2016 / Accepted: 11 July 2016 / Published: 7 August 2016

\begin{abstract}
The electrochemical behaviour and detection of $o$-nitrophenol $(o-\mathrm{NP})$ and $p$-nitrophenol ( $p$-NP) has been studied on a gold nanoparticle - nickel dimethylglyoxime complex (NiDMG) modified glassy carbon electrode (GCE). The electrode was prepared by drop coating nickel dimethylglyoxime complex on a GCE followed by the electrodeposition of gold nanoparticle. Each step in the electrode modification was characterised by cyclic voltammetry (CV), electrochemical impedance spectroscopy (EIS), scanning electron microscopy (SEM) and high resolution scanning electron microscopy (HRSEM). The results showed that nickel dimethylglyoxime complex /gold nanoparticles electrode had improved conductivity, reversibility, and electron transfer rate in selected redox probe than the unmodified GCE. The GCE/NiDMG-AuNP electrode was used in the determination of $o$-NP and $p$-NP in water. Under the optimal conditions, detection limits of $0.58 \mu \mathrm{M}$ and $0.103 \mu \mathrm{M}$ were calculated for $o$-NP and $p$-NP respectively. The GCE/NiDMG-AuNP electrode was applied to real sample and the effect of interferences were studied.
\end{abstract}

Keywords: nitrophenol; gold nanoparticles, nickel dimethylglyoxime, square wave voltammetry.

\section{FULL TEXT}

(C) 2016 The Authors. Published by ESG (www.electrochemsci.org). This article is an open access article distributed under the terms and conditions of the Creative Commons Attribution license (http://creativecommons.org/licenses/by/4.0/). 